
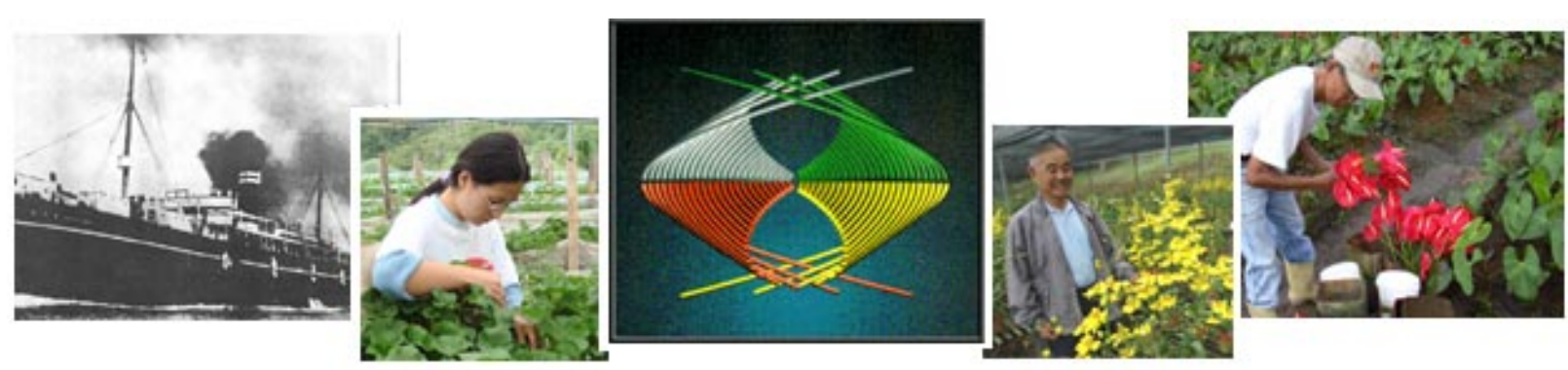

\title{
Breve histórico (até a década de 1980) da produção de flores por imigrantes japoneses no Brasil $^{(1)}$
}

NOBUHIRO TSUBOI ${ }^{(2)}$

\begin{abstract}
Desde Julho de 2006 tenho me dedicado em pesquisar e escrever sobre a História da Floricultura no Brasil. O livro será publicado em português em julho de 2008, abordando a demanda e a produção de flores desde 1940 até o presente, fazendo referência não só aos japoneses, mas a todos os produtores de flores do Brasil. Como o tempo disponível para a pesquisa é limitado, o texto abordará principalmente a atividade desenvolvida no Estado de São Paulo. O livro descreve a história das quatro principais regiões produtoras (Holambra, Atibaia, Mogi das Cruzes e Ibiúna) e as experiências de comércio da Cooperativa Agropecuária de Holambra e da Cooperativa Veiling, também localizada em Holambra. Também pesquisei o histórico da produção de flores por imigrantes da Itália, Alemanha e de outros países, desde o início do século 20, que também será sumariamente incluído no livro. Aqui pretendo fazer uma breve introdução à demanda por flores e à produção de flores por japoneses no Brasil. Neste artigo o termo "produção de flores" refere-se à produção com o objetivo de gerar lucros ou benefícios no âmbito comercial.
\end{abstract}

\section{OHISTÓRICODOS IMIGRANTESJAPONE- SES NO BRASIL}

Os primeiros imigrantes Japoneses aportaram no Brasil em 1908 e até 1988 mais ou menos 243 mil pessoas migraram para o Brasil, com exceção do período de guerra. Antes da Segunda Guerra Mundial havia em torno de 189 mil imigrantes no Brasil ${ }^{(3)}$. Muitos trabalharam em fazendas de café por meio de longos contratos. Após o vencimento dos mesmos, começaram a mudar-se para os grandes centros e seus subúrbios, movimentação que aumentou após a década de 1930.

Após a Segunda Guerra Mundial e até 1988 mais ou menos 54 mil imigrantes chegaram ao Brasil, sendo que $90 \%$ destes aportaram nas décadas de 1950 e 1960. A maioria dos imigrantes japoneses desse período se engajou em atividades agrícolas e se instalou em grandes cidades e seus subúrbios. Esses imigrantes não tinham recursos suficientes para financiar grandes propriedades e muitos se tornaram pequenos produtores rurais.

Como se sabe, a industrialização e a urbanização no Brasil começaram na década de 1930. Isso elevou o crescimento da população nas grandes cidades, resultando no aumento da compra de batatas, vegetais e frutas frescas já que nas áreas urbanas estes não podiam ser produzidos em quantidade suficiente para suprir a demanda. A tabela 1 mostra o aumento da população no Brasil de 1940 a 2000; a população de 12,8 milhões de pessoas em 1940 aumentou para 137,9 milhões em 2000, mais de dez vezes ${ }^{(4)}$. A taxa anual de crescimento populacional foi de até 3,09\% na década de 1940, 2,89\% na de 1960 e 2,48\% na década de 1970, sendo que no município de São Paulo foi maior que no restante do Brasil.

Esse cenário mostra como a demanda por batata, vegetais e frutas aumentou rapidamente já que esses produtos são essenciais tanto para a sobrevivência da classe rica da população como para a classe urbana mais pobre. A urbanização e industrialização trouxeram juntas a procura por esses alimentos. A demanda crescente formou novos mercados para esses produtos e respectivos produtores. Naquela época, consumidores e produtores não tinham nenhuma relação como os consumidores de flores e suprimentos, que mantêm estreita relação, como será explicado posteriormente. Logo, quem tinha interesse e habilidade para a produção de alimentos tornava-se tranquilamente um novo produtor.

O movimento de imigrantes japoneses das fazendas de café e a chegada dos imigrantes no pós-guerra ocorreram concomitantemente com o aumento da demanda por alimentos. Naquela época o consumo era muito maior que a oferta, e isso gerou grandes receitas aos produtores, que por sua vez não precisavam de grandes fazendas para manter a produção. Foi nesse tipo de atividade que grande parte dos imigrantes se engajou.

\footnotetext{
(1) Tradução de Alberto Henrique Ricordi, graduando em Engenharia Agronômica, ESALQ, USP.

(2) Professor Doutor aposentado da Universidade de Tsukuba, Japão

(3) Statistics on Immigrants, JICA, 1990.

(4) IBGE, Censo Populacional, 2000.
} 
Sob essas circunstâncias os produtores rurais japoneses se estabeleceram produzindo batata, vegetais e frutas antes da Segunda Guerra Mundial e durante as décadas de 1950 e 1960. A situação era quase a mesma em relação à demanda por flores, porém a história foi um pouco diferente, pois naquela época não havia muitos japoneses envolvidos nessa atividade.

\section{TENDÊNCIAS DO CONSUMO DEFLORESNO BRASIL}

Flores não são produtos agrícolas para a sobrevivência da população como a batata e o tomate, e a maioria dos consumidores se dividia em rica e alta classe média, antes da Segunda Guerra Mundial. Esse cenário fez a diferença nas tendências de consumo e produção de flores como se verá adiante. Esse é um dos principais motivos pelo qual não havia muitos japoneses e descendentes engajados na produção de flores e tam bem porque permaneceram fora da atividade mesmo após a Segunda Guerra Mundial.

A urbanização e a industrialização aumentaram a população com maior poder aquisitivo e permitiram o surgimento dos novos ricos, pessoas que investiram em fábricas e atividades em ascensão. Isso contribuiu para o aumento da demanda por vegetais e frutas, como também por flores, porém em menor escala, já que os ricos e a classe média alta formavam uma menor parcela da população que tinha recursos para esse tipo de consumo. Se esse aumento de demanda tivesse estimulado fornecedores, a produção de flores em escala comercial cresceria antes da Segunda Guerra Mundial. Porém a população teve que aguardar o fim da Segunda Guerra Mundial para que ocorresse um desenvolvimento do setor, como será explicado adiante.

Até a década de 1940 , os principais consumidores de flores eram as famílias ricas, mas estas não compravam de terceiros. Produziam as próprias flores nas suas grandes casas ou nas próprias fazendas, com jardineiros e empregados próprios. Logicamente, não podiam produzir todas as plantas e espécies, ou seja, não eram auto-suficientes. Para preencher essa lacuna, eles compravam pequenos volumes de fornecedores. Outro aspecto importante é que essa pequena demanda não era suficiente para a formação de um mercado de flores como o formado pelos vegetais e frutas.

A relação entre os ricos consumidores e os fornecedores de flores continuou de geração em geração, tornando-se muito estreita. Essa relação permitiu que os fornecedores ocultassem a crescente demanda e serviu para a exclusão de novos investidores. Eles não precisavam ficar atentos às novas tendências do mercado, pois seus clientes eram fiéis e estáveis. Por outro lado, novos produtores tinham dificuldades para entrar nessa estreita relação: fornecedor-consumidor. A demanda por flores criada pela industrialização e pela urbanização permaneceu oculta até metade da década de 1950.

Após a década de 1930 chegaram novos imigrantes da Europa e alguns deles se envolveram com a produção de flores. Mas eles não perceberam a grande demanda que havia, pois essa estreita relação entre fornecedores e consumidores fazia parte da cultura européia. Grandes oportunidades para o mercado de flores estavam aguardando os imigrantes do Japão e da Holanda.

\section{ALGUMAS CONQUISTAS DOS IMIGRANTES JAPONESES}

Há uma publicação de "Papéis e conquistas de imigrantes japoneses no Brasil"(5) na livraria da Sociedade Brasileira de Cultura Japonesa, em São Paulo, publicada pelo Ministro de Relações Externas do Japão para celebrar o aniversário de 70 anos da imigração japonesa ao Brasil, em 1978. Em seguida citarei algumas conquistas no setor de flores retiradas dela.

Em São Paulo, desde a década de 1930, os imigrantes japoneses aumentaram o fluxo de colonos para produtores familiares independentes e da agricultura extrativa para a intensiva. Eles introduziram e melhoraram vegetais e frutas, e aumentaram a produção e o consumo. O mercado de flores no Largo do Arouche, o primeiro mercado aberto de flores em São Paulo, no começo dos anos 40, era ocupado principalmente por portugueses, porém no final da década, alguns japoneses surgiram como

Tabela 1. Índice médio anual por década do aumento populacional em relação à média anual do período anterior

\begin{tabular}{|c|c|c|c|c|c|c|}
\hline \multirow{3}{*}{ Ano } & \multicolumn{2}{|c|}{ Brasil } & \multicolumn{2}{|c|}{ Estado de São Paulo } & \multicolumn{2}{|c|}{ Cidade de São Paulo } \\
\hline & População & $\begin{array}{c}\text { Aumento } \\
\text { anual } \\
\end{array}$ & População & $\begin{array}{c}\text { Aumento } \\
\text { anual } \\
\end{array}$ & Populalção & $\begin{array}{c}\text { Aumento } \\
\text { anual }\end{array}$ \\
\hline & (milhares) & $\%$ & (milhares) & $\%$ & (milhares) & $\%$ \\
\hline$\overline{1940}$ & 41.236 & - & 7.180 & - & 1.326 & - \\
\hline 1950 & 51.944 & 2,34 & 9.134 & 2,44 & 2.198 & 5,18 \\
\hline 1960 & 70.070 & 3,04 & 12.824 & 3,45 & 3.781 & 5,57 \\
\hline 1970 & 93.139 & 2,89 & 17.712 & 3,28 & 5.924 & 4,59 \\
\hline 1980 & 119.003 & 2,48 & 25.040 & 3,52 & 8.493 & 3,67 \\
\hline 1991 & 146.825 & 1,93 & 31.589 & 2,13 & 9.646 & 1,16 \\
\hline 2000 & 169.799 & 1,63 & 37.032 & 1.78 & 10.434 & 0.88 \\
\hline
\end{tabular}

Fonte: IBGE, Population, Census, Demographic Census 2000-Results of the Universe (Versão em inglês). Nota: A taxa de crescimento anual na linha de 1950 significa a taxa entre 1940 e 1950.

\footnotetext{
${ }_{(6)}^{(5)}$ Papéis e conquistas de imigrantes japoneses no Brasil. 330 p., 1978. (japonês)

(6) Holambra Een Nederlandse Landbouwcoöperetie in Brazilië, p.37-38, Cooperativa Agropecuária Holambra. 1981.
} 
grandes fornecedores. A presença dos japoneses aumentou gradualmente acompanhando a mudança da feira para a Praça Franklin Roosevelt e para o Pacaembu, última feira de flores na cidade de São Paulo. Eles eram os principais fornecedores quando o mercado de flores de São Paulo (atual CEAGESP) abriu em 1966.

De acordo com os dados daquela publicação, em 1977, os produtores japoneses ocupavam 72,2\% dos 443 boxes do mercado de flores na CEAGESP. Quando a Cooperativa Agropecuária Holambra abriu sua seção de flores, havia sete produtores holandeses na região de Holambra, e em 1980 havia apenas 25 produtores membros da cooperativa ${ }^{(6)}$, enquanto que, em 1983, a Associação Central de Flores e Plantas Ornamentais do Estado de São Paulo, formada por imigrantes japoneses, tinha 321 produtores associados. Como havia produtores que não participavam da associação, pode-se estimar que mais de 400 produtores japoneses ocupavam a Grande São Paulo e seus subúrbios.

\section{POR QUE OS PRODUTORES JAPONESES NOTA- RAMAOPORTUNIDADE"OCULTA”?}

Os imigrantes japoneses eram novos no Brasil, pois só eram aceitos imigrantes da Europa e da América do Norte antes do século XX. Muitos deles não foram influenciados pela cultura européia e não tinham nenhum preconceito ao Brasil, pois a cultura japonesa é muito diferente da cultura européia. Como para eles era muito difícil de entender a estreita relação entre produtores e consumidores, foi fácil notar a demanda existente e logo passaram a produzir flores.

Do século XVII ao século XIX os produtores japoneses desenvolveram um pensamento mercantilista por questão de sobrevivência. O pensamento mercantilista significa enxergar cuidadosamente as necessidades dos consumidores e produzir mercadorias para suas demandas. Os imigrantes japoneses mudavam-se para as grandes cidades procurando mercados que sustentassem suas pequenas produções. A maioria começou produzindo frutas e vegetais, enquanto alguns começaram produzindo flores antes mesmo da Segunda Guerra Mundial, em São Paulo e em seus subúrbios, crescendo gradualmente como já foi mencionado.

Após a Segunda Guerra Mundial, japoneses interessados em produzir flores migraram para o Brasil. Eles sabiam que a produção de flores era crescente no Japão, já nos anos 40 e 50, e acreditavam que o mercado de flores no Brasil cresceria rapidamente. Nas décadas de 1950 e 1960, para muitos japoneses o Brasil era um país muito mais desenvolvido que o Japão derrotado pelos americanos e outros na Segunda Guerra Mundial e tinha um futuro brilhante.
Por favor, observe a tabela 1 novamente. A taxa de crescimento anual da população está diminuindo desde a década de 1970, e era apenas 0,88\% em 1990. Isso significa que o aumento natural da demanda por flores devido ao aumento de população já havia cessado. Até a década de 1980 a demanda por flores era sempre superior à oferta e produtores gozavam de um "período orientado pela produção". A tendência da relação consumidor-fornecedor tem mudado desde a metade dos anos 90 e produtores se depararam com a nova era do "período orientado pelo consumo". Conclusão: os produtores tiveram que mudar sua a visão até o fim da década de 1980.

\section{COMO OS JAPONESES LIDARAM COMANOVA ERAORIENTADAPELOCONSUMO}

De fato, as conquistas dos japoneses no Brasil até a década de 1980 foram grandes. Desde a década de 1990, as tendências do mercado de flores têm mudado. Isso significa a não sobrevivência sem a mudança de visão para enfrentar a nova era. Mas o que é a nova era?

As conquistas de os japoneses até a década de 1980 foram baseadas em um período orientado pela produção. Apesar dos japoneses serem familiarizados com o pensamento mercantilista, eles não tinham muitas chances de mostrar suas habilidades na era orientada pela produção porque os produtores vendiam tudo que produziam. As conquistas citadas acima são daquele tempo e, atualmente, sua participação está diminuindo. O tempo crescimento natural do mercado de flores acabou, porque a taxa de crescimento da população da cidade de São Paulo diminuiu para $1,16 \%$ nos anos 80 para um terço dos anos 70 e para apenas $0,88 \%$ nos anos 90 .

Agora, as tendências da relação consumidorfornecedor estão mudando de uma era orientada pela produção para uma era orientada pelo consumo. Na nova era a produção não é vendida se esta não é produzida com a qualidade exigida pelo consumidor. Os produtores precisam descobrir quem são seus consumidores e quais suas exigências. Agora é a hora de exibir o "pensamento mercantilista” japonês. Eles podem fazê-lo?

De forma geral, não é fácil para alguém bemsucedido no mercado orientado pela oferta mudar sua visão e se adequar ao mercado orientado pelo consumo. Produtores na era orientada pelo consumo não podem sobreviver sem um "pensamento mercantilista". Tenho dúvidas se a segunda geração de japoneses no Brasil entende esse pensamento. Um problema sério para eles é que a primeira geração diminui gradativamente e a geração subseqüente não a sucede. 